\title{
Power Loss Analysis of a Radial Distribution Feeder by using Distributed Generator
}

\author{
Mushtaq.A.K.Khattak ${ }^{1}$ Amjadullah khattak ${ }^{2}$, Mohammad Ismail ${ }^{3}$,Waqar Hussain ${ }^{4}$, Jahangir Bahadur ${ }^{5}$, Najum saqib ${ }^{6}$ \\ 1, 2,3,4,5,6 University of Engineering and Technology, Peshawar \\ M.A.K.Khattak@uetpeshawar.edu.pk ${ }^{1}$ \\ Received: 30 July, Revised: 05 August, Accepted: 10 August
}

\begin{abstract}
The desire and required place for providing electricity i.e. Homes, industries, markets, etc. are far away from the place where electricity is produced (power stations). It results in low efficiency and also increases the cost. It has so many dis-advantages. It may also have environmental and security issues as well.

The primary objective of this resaerch is to evaluate and reduces the percentage loss. The power loss is performed for different locations. The result shows the appropriation of distributed generator in to power system.
\end{abstract}

Keywords - losses reduction, Distributed generator, Radila Feeder

\section{INTRODUCTION}

Nowadays the generation is producing new technologies. They aim are providing facilities to users. Which includes good quality and high power as well. They have promised to generate electricity with high efficiency and producing very low pollution. $[1,3,6]$.

Distributed Generation is acknowledged through a number of names like On-Site generation, Dispersed Generation, Decentralized Generation, or Embedded Generation. It is a small scaleelectricity generating technology(typically in the range of $50 \mathrm{~kW}$ up to a hundred $\mathrm{MW}$ ) and used to supply anchoice to or enhancementof the historically current electric energy structures such as hydropower system, thermal power system, nuclear energydevice etc [1,5].

Distributedgeneration can be viewed as "taking energy to load". Distributed generation guaranteesto generate electricity withhigh efficiency and lowpollution. Unlike massive central (conventional) massive energy plants, distributed generatorcan be established at or close to the load.Maintenance price for distributed generation such asfuel cells and photovoltaicdevice is pretty low due to thefact of the absence of transferring components $[4,9]$.

Many of these technologies are at the stage of development including micro turbines, wind energy, gas turbines, fuel cell system and many more. This will make the users ease. These advantages include the line loss reduction, reduces the environmental impacts. It also increase the efficiency, power and voltage as well. [5,7].

\section{MODELING OF SYSTEM}

There are following two cases shown in fig 1 and fig 2 .

a) System without the integration of Distributed generator

b) System with the addition of Distributed generator

These two systems have the concentrated0load. The length for these two system have to be assumed L (KM).

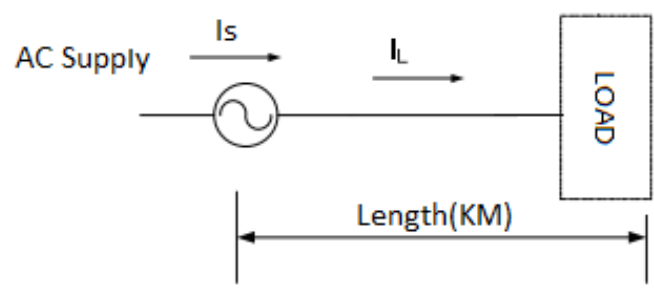

Figure 1. Radial System without integration of Distributed generator

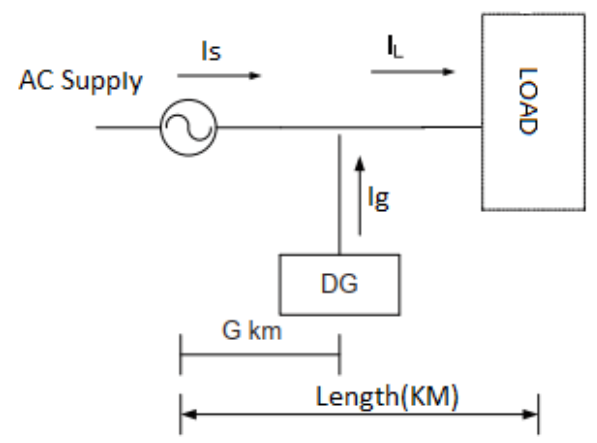

Figure 2. Radial system with the integration of distributed generator

Before analysis the following assumption to be taken:

1. Y-connected load i.e. the phase current(Ip) should be same to line current(IL):

$$
\mathrm{I}_{\text {Phase }}=\mathrm{I}_{\text {Line }}
$$

2. At specified power factor the load consume some real active power. 
3. At lagging leading or unity factor the distribution generator produce real power.

4. $\mathrm{V}_{\mathrm{P}}$ is the value of RMS voltage

5. $\mathrm{V}_{\mathrm{P}}$ is the phasor reference voltage to be chosen

The complex load power is $\mathrm{S}_{\mathrm{L}}=\mathrm{P}_{\mathrm{L}}+\mathrm{JQ}_{\mathrm{L}}$ so

The load absorb the current

$$
\boldsymbol{I}_{\mathrm{L}}=(\boldsymbol{P} L-\boldsymbol{J} \boldsymbol{Q} L) / 3 \boldsymbol{V} P
$$

\section{ANALYSIS LOSS REDUCTION}

When current passes through transmission line the losses occur. The line loses depends on amount of current passes and line resistance.so the losses is to be minimize due to decreased the current or resistance0or the both. When DG is provided in to the load the losses may be reduced due to current passing to some of network part.

\section{A. Analysis of line losses without the distribution generator}

Diagram of the analysis for the system as shown in figure 1.in distribution system line losses is equal to the square times current and resistance.so for three phase system the equation foe line losses as:

$$
\text { L. } L O S S_{B D G}=\frac{r L\left(P_{L}^{2}+Q_{L}^{2}\right)}{3 V_{P}^{2}}
$$

\section{B. Analysis of line losses with integration of distributed generator}

Diagram for the system is shown in figure 2. Let assume that the line is to be short and across that line the voltage drop is neglected.

The DG delivered the complex power which is equal to the $\mathrm{S}_{\mathrm{DG}}=\mathrm{P}_{\mathrm{DG}}+\mathrm{JQ}_{\mathrm{DG}}$

So the output of DG will be given as;

$I_{D G}=\frac{\left(P_{D G}-J Q_{D G}\right)}{3 V_{P}}$

There are two main causes of line loss integrated with DG

1. Line from source to DG Centre.

Line losses for the several allocation of DG to their load

It is clear from figure 2

$\mathrm{I}_{\text {Source }}=\mathrm{I}_{\text {Line }}-\mathrm{I}_{\mathrm{DG}}$

So the line loss equation for the system from source to DG is expressed as

$$
\begin{aligned}
& \text { L. } L O S S_{S-D G} \\
& =\frac{r G\left(P_{L}^{2}+Q_{L}^{2}+P_{D G}^{2}+Q_{D G}^{2}-2 P_{D G} P_{L}-2 Q_{D G} Q_{L}\right)}{3 V_{P}^{2}}
\end{aligned}
$$

2. Line losses from DG location to load Centre
When distributed generator is not allocated between the systems so the line current must be equal to load current, thus the equation for this system is given as:

L. $\operatorname{LOSS}_{D G-S}$
$=\frac{r(L-D G)\left(P_{L}^{2}+Q_{L}^{2}\right)}{3 V_{P}^{2}}$

3. Over all line losses in the system

Line losses in the system is given as in the following equation

$$
\text { L. } \operatorname{LOSSES}_{T}=L . L O S S E S_{S-D G}+L . L O S S E S_{D G-S}
$$

By substituting the equation 5 and equation 6 in the above equation, the following equation gets.

$$
\begin{aligned}
L . \operatorname{LOSSES}_{T}= & \frac{R G}{3 L V_{P}^{2}}\left[P_{L}^{2}+Q_{L}^{2}\right. \\
& +\left(P_{D G}^{2}+Q_{D G}^{2}-2 P_{D G} P_{L}\right. \\
& \left.\left.-2 Q_{D G} Q_{L}\right)\right]
\end{aligned}
$$

\section{Reduction of line loss due to integration of DG in the system}

Reduction of line losses is equal to the difference between integration of DG before in the system and integrate DG in to the system is given in the following equation

$$
\begin{aligned}
& \text { L. Losses } \\
& =L_{\text {Losses }} \text { LogG } \\
& - \text { L. Loss }_{A D G}
\end{aligned}
$$

By substituting the equations in the above equation (8). The following equation gets,

$$
\begin{gathered}
\text { L. Loses }=\frac{R G}{3 L V_{P}^{2}}\left(2 P_{D G} P_{L}+2 Q_{D G} Q_{L}-P_{L}^{2}\right. \\
\left.-Q_{D G}^{2}\right)
\end{gathered}
$$

If the losses in the system is decreased then the L.Loss will indicate the positive sign due to connection of DG. And inversely when system has higher losses then L.Loss will show negative sign.

\section{Per-unit reduction of line losses}

Per-unit rduction of L.Losses is equal to reduction of L.Losses to the L.Losses without the integration of DG Therefore

PULLR $=\frac{\text { L.Losses }}{\text { L. Losses }}$

By putting the two equations line the above equation (10), gets 


$$
\begin{aligned}
& P U L L R=\frac{G}{L\left(P_{L}^{2}+Q_{L}^{2}\right)}\left(2 P_{D G} P_{L}+2 Q_{D G} Q_{L}-P_{L}^{2}-\right. \\
& \left.Q_{D G}^{2}\right)
\end{aligned}
$$

So, percentage of line loss reductionis expressed as: $\%$ L. Losses $=$ PULLR $\times 100$

\section{E. Both the load and DG power factor at the time operating:}

There are four different conditions which are given below.

Condition1: Load has leading and DG has lagging power factor.

Condition 2: Load has lagging and DG has leading power factor.

Condition 3: Load and DG having same leading power factor. factor

Condition 4: Load and DG having same lagging power

From above discussion it's expressedthat the condition 3 and 4 give the actualresult whereas the condition 1 and 4 gives the actual results.

The equation of PURLL is given below for two dissimilar conditions

For condition 3 and 4 :

\section{PULLR}

$=\frac{Z G\left(P \cdot F_{L}\right)^{2}}{L}\left[2-\frac{Z}{\left(P \cdot F_{G}\right)^{2}}\right.$

$\left.-\frac{2 \sqrt{1-\left(P . F_{L}\right)^{2}} \times \sqrt{1-\left(P . F_{G}\right)^{2}}}{\left(P . F_{L}\right)^{2} \times\left(P . F_{G}\right)^{2}}\right]$

For condition 1 and 4 :

$$
\begin{aligned}
& \text { PULLR } \\
& =\frac{Z G\left(P . F_{L}\right)^{2}}{L}\left[2-\frac{Z}{\left(P . F_{G}\right)^{2}}\right. \\
& \left.+\frac{2 \sqrt{1-\left(P . F_{L}\right)^{2}} \times \sqrt{1-\left(P . F_{G}\right)^{2}}}{\left(P . F_{L}\right)^{2} \times\left(P . F_{G}\right)^{2}}\right]
\end{aligned}
$$

\section{RESULTS AND DISCUSION}

\section{A. Reduction of line losses Analysis Conclusion}

The impact of DG on line losses it assumed that DG should be kept at the Centre of feeder line that is $\mathrm{DG}=1$ and take the length $2 \mathrm{~km}$ of system i.e. $\mathrm{L}=2 \mathrm{~km}$. the power factor of $\mathrm{DG}$ and load is too constant. The twenty five different values is taken and changing the output of DG and the load is constt at $2.3 \mathrm{pu}$. To use the equation 12 to find the different values of DG output power. It's shown in the figure 3

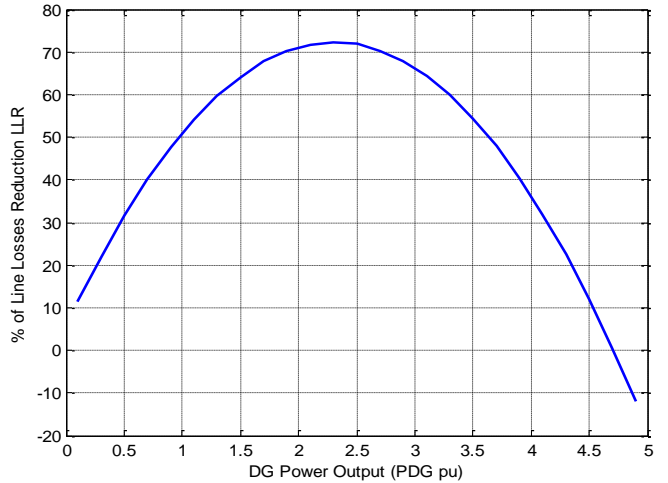

Figure 3. Reduction in system losses by varying DG output power

The above figure show that due DG in the system it reduce the losses. And DG delivers active and reactive power to the load Centre. And it is clearly that the reactive and active power is supply by DG to their load center.When the location of DG and their rating are not well matched then it's a high losses in the system.

A. Changing of DG position at different location

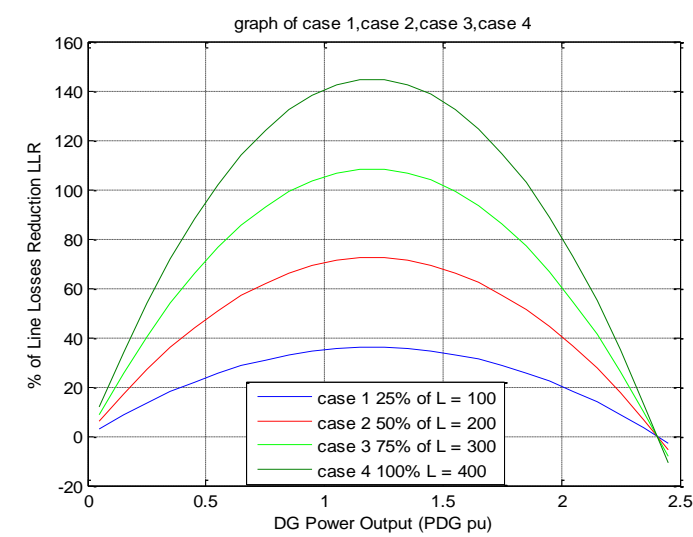

Figure 4. Line loss reduction by varying the location of DG and output power

The position of DG at four different location is to be consider.so it's assumed that DG is varying along the feeder line it would be taken four different location.

Location 1: fist DG keep at the $25 \%$ of total length

Location 2: second DG keeps at the $50 \%$ of total length

Location 3: third DG keeps at the $75 \%$ of total length

Location 4: at the end DG keep at $100 \%$ of total length

From above figure it is clearly shows that when DG near to the load the system losses is reduced .near the DG to load less will be the losses. This will only possible when the load and DG both are well matched. The total load can't consume the power which is given by DG. So at distance of DG from source there will be higher losses. 


\section{B. At different power factor the system Analysis}

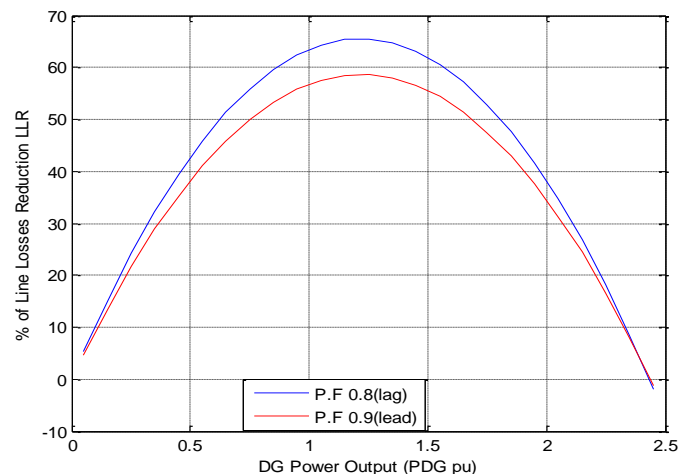

Figure 5. Line loss reduction by varying DG location and power factor

From above figure its show that when there is lagging power factor there is more reduction in the system and providing the DG reactive power to the load. DG power factor either lag or lead to calculate the reduces of line losses. Consider the two different values of DG power factor to analysis the reduction of loss.

\section{CONCLUSION}

This paper shows the reduction of line losses of radial distribution when DG is incorporate in the system. From result it clearly shows the line losses reduction. A simple distribution system is taken and incorporates the DG. The location, rating and power factor of DG is important to reduce the line losses.

Similarly, when DG is closer the load there is a reduction in line losses and at the distance from source to load be high losses in the system. This would be possible only when the load and DG both are well matched.

The purpose of this research is to integrate the one DG in a system to reduce line losses. Further if clearly result look then many DG incorporate in the distribution feeder will give better results.

\section{REFERENCES}

[1] K. Dang, J. Yu, T. Dang, and B. Han, "Benefit of distributed generation on line loss reduction," in 2011 International Conference on Electrical and Control Engineering, 2011, pp. 2042-2045.

[2] A. Kumar and W. Gao, "Voltage profile improvement and line loss reduction with distributed generation in deregulated electricity markets," TENCON 2008 - 2008 IEEE Region 10 Conference, pp. 1-6, Nov. 2008.

[3] P. Chiradeja, "Benefit of Distributed Generation: A Line Loss Reduction Analysis," in 2005 IEEE/PES Transmission \& Distribution Conference \& Exposition: Asia and Pacific, pp. 1-5.

[4] Sonderegger, R. C., Henderson, D., Bubb, S., and Steury, J.,"Distributed Asset Insight,“ IEEE Power\&Energy Magazine, pp. 32-39, May/June 2004.

[5] Puttgen, H. B., Macgregor, P. R., and Lambert F.C., "Distributed Generation: Semantic Hype or the Dawn of a New Era?," IEEE Power\&Energy Magazine, pp. 22-29, January/February 2003

[6] A. D. T. Le, M. A. Kashem, S. Member, M. Negnevitsky, and G. Ledwich, "Optimal Distributed Generation Parameters for Reducing Losses with Economic Consideration,”pp. 1-8, 2007.
[7] P. Chiradeja, R. Ramakumar, and L. Fellow, "An Approach to Quantify the Technical Benefits of Distributed Generation," vol. 19, no. 4, pp. 764-773, 2004.

[8] R. Abbasi, "Reduction of Transmission Line Losses Using VLSI Interconnect," Procedia Engineering, vol. 30, no. 2011, pp. 10-19, Jan. 2012

[9] T. Q. D. Khoa, P. t. t. Binh, and H. b. Tran, "Optimizing Location and Sizing of Distributed Generation in Distribution Systems," in 2006 IEEE PES Power Systems Conference and Exposition, 2006, pp. 725-732.

[10] H. Iyer, S. Member, S. Ray, S. Member, R. Ramakumar, and L. Fellow, "Assessment of Distributed Generation Based on Voltage Profile Improvement and Line Loss Reduction," pp. 1-6, 2010.

[11] P. A.-d-vimal Raj, S. Senthilkumar, J. Raja, S. Ravichandran, and T. G. Palanivelu, "Optimization of Distributed Generation Capacity for Line Loss Reduction and Voltage Profile Improvement Using PSO,” vol. 10, no. 2, pp. 41-48, 2008.

[12] W.-T. Huang and S.-T. Chen, "Line Loss Reduction by Distribution System Upgrading from Radial to Normally Closed-Loop Arrangement," 2009 Ninth International Conference on Hybrid Intelligent Systems, pp. 334-339, 2009.

[13] H. B. Puttgen, P. R. Macgregor, and F. C. Lambert, 2003. Distributed generation: Semantic hype or the dawn of a new era? vol. 1, p. 22-29. Power and Energy Magazine, IEEE.

[14] R. K. Rajput, 2005. Internal Combustion Engines: Laxmi Publications.

[15] D. M. Tagare, 2011. Electricity Power Generation. The Changing Dimensions: Wiley

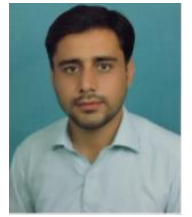

Mushtaq Khattak who graduated from University of WAH in 2015. He holds B.Sc degree in Electrical Power Engineering.He is currently postgraduate student in M.Sc Electrical Power Engineering at UET Peshawar. 